\title{
TEORIA DA AGENCIA, STEWARDSHIP E STAKEHOLDERS: UM ENSAIO SOBRE SUA RELEVÂNCIA NO CONTEXTO DAS ORGANIZAÇÕES
}

\section{AGENCY, STEWARDSHIP AND STAKEHOLDERS THEORIES: AN ESSAY ON ITS RELEVANCE IN THE CONTEXT OF ORGANIZATIONS}

\section{TEORÍA DE LA AGENCIA, STEWARDSHIP Y STAKEHOLDERS: UN ENSAYO SOBRE SU PERTINENCIA EN EL CONTEXTO DE LAS ORGANIZACIONES}

Susana Campos

https://orcid.org/0000-0003-4679-6502

Mestranda do Programa de Pós-graduação em Administração da FEA/USP

E-mail: susanasalessilva@gmail.com

Raquel Costa

https://orcid.org/0000-0003-4850-4323

Doutoranda do Programa de Pós-graduação em Controladoria e Contabilidade da FEA/USP

E-mail: raqsalesc@gmail.com

\section{RESUMO}

Este ensaio analisa comparativamente as principais teorias que norteiam as questões de Governança Corporativa: Teoria da Agência, Teoria do Stewardship e Teoria dos Stakeholders. Com base em estudos clássicos e recentes são apresentadas as origens, conceitos e contrapontos de cada uma delas. A teoria do stewardship confronta os pressupostos individualistas do modelo de ser humano apresentado pela teoria da agência, à medida que busca explorar complexidade de pensamentos e ações do indivíduo. Já a teoria dos stakeholders questiona um dos princípios já consolidados pela problemática da agência, que assume como propósito final da companhia a maximização dos retornos dos shareholders. A teoria da agência é a principal vertente teórica utilizada em estudos do campo. Entretanto, observa-se a crescente tendência de estudos multi teóricos, dada a possível complementaridade dessas teorias. Esse ensaio ainda se posiciona criticamente quanto a aplicabilidade da teoria do stewardship e stakeholders na realidade das organizações.

Palavras-chave: Governança Corporativa. Teoria da Agência. Teoria do Stewardship. Teoria do Stakeholder.

\footnotetext{
Abstract

This essay compares the main theories that guide Corporate Governance issues: Agency Theory, Stewardship Theory, and Stakeholder Theory. Based on classic and recent studies, their origins, concepts and counterpoints are presented. The stewardship theory confronts the individualistic assumptions of the human model presented by agency theory as it seeks to
} 
explore the complexity of the individual's thoughts and actions. The stakeholder theory, on the other hand, questions one of the principles already consolidated by the agency's problem, which assumes the ultimate purpose of the company is to maximize shareholder returns. Agency theory is the main theoretical approach used in the field. However, there is a growing trend of multi-theoretical studies, given the possible complementarity of these theories. This essay still takes a critical stand on the applicability of stewardship and stakeholders theory to the reality of organizations.

Keyword: Corporate Governance. Agency Theory. StewardshipTheory. StakeholderTheory.

\section{Resumen}

Este ensayo compara las principales teorías que guían las cuestiones de gobierno corporativo: teoría de la agencia, teoría de lo stewardship y teoría de los stakeholders. Basado en estudios clásicos y recientes, se presentan sus orígenes, conceptos y contrapuntos. La teoría de lo stewardship confronta los supuestos individualistas del modelo humano presentado por la teoría de la agencia, ya que busca explorar la complejidad de los pensamientos y acciones del individuo. La teoría de los stakeholders, por otro lado, cuestiona uno de los principios ya consolidados por el problema de la agencia, que asume el propósito final de la compañía de maximizar los retornos de los accionistas. La teoría de la agencia es el principal hilo teórico utilizado en los estudios de campo. Sin embargo, existe una tendencia creciente de estudios multiteóricos, dada la posible complementariedad de estas teorías. Este ensayo aún toma una posición crítica sobre la aplicabilidad de la teoría de lo stewardship y los stakeholders a la realidad de las organizaciones.

Palabra clave: Gobierno corporativo. Teoría de la Agencia. Teoría de lo Stewardship. Teoría de los Stakeholders.

\section{INTRODUÇÃO}

A temática da Governança Corporativa vem ganhando cada vez mais atenção no campo dos estudos organizacionais devido a uma série de acontecimentos recentes e tendências globais. De acordo com Becht, Bolton e Roell (2003), são responsáveis por reacenderem este debate, entre outras, questões como: o maior ativismo dos investidores institucionais, a onda de privatizações nos países Europeus e em desenvolvimento, as crises nos mercados emergentes no final do século XX e os escândalos corporativos nos Estados Unidos e Europa, envolvendo fraudes contábeis e financeiras. A essa sucessão de acontecimentos, soma-se a crise financeira global de 2008, que evidenciou diversas falhas dos Conselhos de Administração, principalmente no que diz respeito ao monitoramento de riscos associados ao uso de produtos financeiros complexos (DA SILVEIRA, 2015).

Nesse cenário, torna-se oportuno o estudo das teorias que embasam as relações contratuais existentes entre principal e agente no ambiente empresarial. As principais abordagens utilizadas nas pesquisas no campo da governança corporativa são: Teoria da Agência, Teoria do Stewardshipe Teoria dos Stakeholders.

A Teoria da Agência (JENSEN; MECKLING, 1976) busca compreender os possíveis conflitos decorrentes da relação entre principal e agente e baseia-se em pressupostos a respeito da organização e do ser humano. No cenário proposto pelos autores, predomina uma concepção de ser humano individualista e maximizador de utilidade. Contrastando com a teoria da agência, a StewardshipTheory(DAVIS; SCHOORMAN; DONALDSON, 1997)tem origem nos campos da psicologia e sociologia e centra-se nas situações em que os agentes se mostram motivados para agir em favor do principal (DONALDSON; DAVIS, 1991). Nessa 
abordagem, o modelo de ser humano utilizado é aquele cujo comportamento é próorganização e vê maior utilidade no coletivismo do que no individualismo. Já a Teoria dos Stakeholders, discutida por Freeman (1984), difere da teoria da agência no que diz respeito ao propósito da organização. Enquanto a primeira defende que a empresa possui responsabilidade para com todos os envolvidos no negócio (fornecedores, consumidores, sociedade, entre outros), a segunda considera apenas o compromisso da empresa para com seus acionistas.

Assim, este estudo se propõe a analisar comparativamente essas três teorias, sua aplicabilidade empírica e suas contribuições para o pensamento organizacional no âmbito da governança corporativa. Dadas as especificidades e pressupostos admitidos na construção de cada abordagem, a contraposição das ideias enriquece a discussão de relevância do elo principal-agente no contexto corporativo. Esse ensaio mostra a teoria da agência como principal norteadora dessa relação e a teoria do stewardship como um caso específico que aprimora seu entendimento, à medida que adiciona novas variáveis aos possíveis cenários existentes. Além disso, estudos recentes indicam uma tendência da utilização de abordagens multi teóricas a fim de analisar com mais profundidade a realidade das organizações (ABERG; BANKEWITZ; KNOCKAERT, 2019; MADISON; HOLT; KELLERMANNS; RANFT, 2016).

Este artigo está organizado em três seções. A primeira seção, introdução, explora o contexto no qual o tema está inserido. A segunda seção discute, por meio de estudos clássicos e recentes, as três teorias que embasam as pesquisas organizacionais: teoria da agência, teoria do stewardship e teoria dos stakeholders. Em relação a teoria da agência são apresentados aspectos sobre sua origem, correntes de estudos e visões críticas de pressupostos incorporados por ela. A seguir, é abordada a teoria do stewardship e sua contribuição para o pensamento corporativo. Por fim, são expostas a origem, principais ideais e críticas à teoria dos stakeholders. A seção três conclui.

\section{REFERENCIAL TEÓRICO}

\subsection{TEORIA DA AGÊNCIA}

\subsubsection{Origem}

Desde o surgimento da Companhia das Índias Orientais, primeira corporação do mundo com ações livremente negociadas, a consciência da governança corporativa já se fazia presente, bem como a busca pelo entendimento das relações que compunham esse sistema. Com o advento das grandes organizações americanas na década de 70 , no contexto da Revolução Industrial, a discussão da relação entre propriedade e gestão ganhou ainda mais importância, tanto para a academia, quanto para o ambiente corporativo. Começaram a surgir, então, vários estudos nesse sentido. Wilson (1968) e Arrow (1970), a fim de compreender o cerne do relacionamento entre as partes da organização, descreveram esse 'contrato', abordando os problemas decorrentes do compartilhamento de riscos entre grupos e indivíduos.

Tais estudos impulsionaram o surgimento da Teoria da Agência cuja ideia central, a respeito da separação entre propriedade e gestão, já tinha sido proposta por Berle e Means em 1932 e formalizada mais tarde por Jensen e Meckling em 1976. Essa teoria tem como pano de fundo a relação entre uma parte (principal) que delega autoridade a outra parte (agente) para agir de acordo com seus interesses. Esta relação pode apresentar problemas quando as partes 
possuem, além de diferentes atitudes em relação ao risco, objetivos e funções distintas dentro da instituição.

O relacionamento de agência é compreendido pelo uso de contratos como unidade básica de análise, conforme proposto por Jensen e Meckling (1976) e amplamente explorado pela literatura organizacional e financeira (FAMA; JENSEN, 1983a). Nesse sentido, Eisenhardt (1989) retoma a ideia de que a teoria da agência tem como foco determinar a forma de contrato mais eficiente a partir de pressupostos a respeito das organizações, do comportamento do ser humano e das informações disponíveis. A autora, em seu paper que analisa e revisa aspectos da teoria da agência, traz duas correntes dentro dessa linha de estudo: Positivista e Principal-Agente.

\subsubsection{Linha Positivista}

A corrente positivista, segundo Eisenhardt (1989), tem como objetivo identificar as situações em que é provável a ocorrência de conflitos de agência e propor os mecanismos apropriados para limitar o comportamento oportunista do gestor. Jensen e Meckling são importantes representantes da linha positivista. Em seu trabalho seminal, publicado em 1976, os autores buscam explorar como a participação no capital da empresa por parte dos gestores é capaz de alinhar seus interesses com o principal. Para isso os autores propõem a "Teoria de Estrutura de Propriedade das Firmas". Na construção dessa teoria, são consideradas questões centrais e básicas de direito, agencye finanças, como definição dos direitos de propriedade e custos de agência.

A definição dos direitos de propriedade diz respeito à especificação de direitos individuais que acabam por determinar como os custos e recompensas serão alocados entre os participantes de uma organização. Esses direitos, que são definidos por meio de contratos, vão depender da natureza da relação contratual entre agente e principal. Já em relação aos custos de agência, os autores expõem a questão como consequência da relação contratual em que ambas as partes envolvidas são maximizadoras de utilidade e que, por isso, há razões suficientes para crer que nem sempre o agente agirá conforme os interesses do principal. Assim sendo, Jensen e Meckling (1976) afirmam que os custos de agência envolvem os custos que o principal assume a fim de monitorar o comportamento do agente, as despesas de bonding incorridas pelo agente, ou seja, as despesas que o agente incorre para comprovar seu comprometimento, e mais um custo residual que não pode ser evitado e nem mitigado por meio de controles. A partir da breve abordagem desses conceitos, os autores apresentam a associação entre 'separação de gestão e propriedade' nas corporações modernas e os problemas de agência, construindo, assim, sua teoria.

O primeiro artigo de Fama e Jensen publicado em 1983, também contribuiu de forma significativa com a linha positivista, mostrando o Conselho de Administração como um importante mecanismo e sistema de informação útil ao acionista no monitoramento do comportamento oportunista do gestor. Os autores iniciam sua narrativa chamando a atenção para o fato de a organização ser, em sua essência, um conjunto de $\operatorname{contratos}^{1}$, formais e não formais, entre seus participantes.

Tais contratos, ainda segundo os autores, devem especificar os 'reclamantes residuais', alocar os passos do processo de decisão da organização e definir ferramentas de controle de problemas de agência. Os reclamantes residuais são aqueles que assumem os riscos e

1 Os custos de transação dos contratos já haviam sido discutidos por estudiosos como Ronald Coase (1960), Douglass North (1991) e Oliver Williamson (1981). De acordo com o Teorema de Coase, os custos de transação inerentes aos contratos sociais envolvem negociação, redação e garantia do cumprimento dos mesmos. 
contratam os direitos de possuir o fluxo de caixa líquido de uma operação, ou seja, os shareholders. Dependendo do seu formato, esses reclamantes podem ser mais ou menos restritos em relação a sua participação no processo decisório da organização.

O processo de decisão descrito por Fama e Jensen (1983a) se dá em 4 etapas: (1) iniciação (propostas para a utilização dos recursos e estruturação de contratos); (2) ratificação (escolha se as iniciativas propostas serão implementadas ou não); (3) implementação (execução das decisões ratificadas) e (4) monitoramento (avaliação de desempenho dos agentes e compensação). A separação entre gestão e propriedade consiste na combinação desses passos em: Gerenciamento de Decisões (1 e 3) e Controle de Decisão (2 e 4). A partir do que foi exposto, Fama e Jensen (1983a) analisam a separação e a combinação entre esses fatores em diferentes tipos de organizações, adicionando em sua análise a variável 'tomada de risco'.

A combinação entre gestão e controle de decisão com a tomada de riscos é eficiente em apenas algumas situações. Em organizações pequenas e não complexas ${ }^{2}$, a eficiência vem por meio da concentração das atividades de gerenciamento e controle de decisões no mesmo agente. Porém, tal combinação faz com que os 'reclamantes residuais' tenham pouca proteção contra as eventuais ações oportunistas dos gestores. Nesse caso, uma possível solução seria restringir os reclamantes residuais a tomadores de decisão. Exemplos de organizações que funcionam sob esse sistema são: pequenas parcerias e corporações fechadas que operam com baixa escala de produtos e serviços (FAMA; JENSEN, 1983a).

Organizações em que há a separação entre gestão e propriedade têm como importante característica o fato de serem organizações complexas ${ }^{3}$, o que envolve custos de transferência de conhecimento. Sendo assim, o mais eficiente seria delegar aos possuidores desse conhecimento específico os passos 1 e 3 do processo de decisão, efetivando assim, a separação entre propriedade e gestão. Outra característica relevante a ser analisada é a dispersão entre os reclamantes residuais. Se por um lado essa dispersão traz vantagens em relação ao compartilhamento de risco, por outro lado o envolvimento de todos no processo de decisão é custoso.

Fama e Jensen (1983a) apresentam, para cada tipo de organização (companhias abertas, parcerias profissionais, organizações sem fins lucrativos e mútuos financeiros), suas características contratuais, a importância do conhecimento específico, bem como os mecanismos de monitoramento dos gestores, a quem foram delegadas importantes etapas do processo de decisório. Os autores finalizam seu trabalho apresentando o Conselho de Administração como o principal mecanismo que permite a separação eficiente entre gestão e propriedade, uma vez que este possui, entre outras, a função de ratificar e monitorar as ações dos gestores e assegurar a sobrevivência da organização.

Estudos recentes inseridos na abordagem positivista exploram características dos mecanismos de governança em diversos tipos de organizações. Os Conselhos de Administração, particularmente, têm ganhado crescente atenção dos pesquisadores, devido aos escândalos corporativos que ocorreram nos Estados Unidos e Reino Unido no final dos anos 90 e início dos anos 2000 envolvendo a direção de grandes corporações. Nesses estudos, predominam questões associadas ao agencye a independência do board (ABERG et al., 2019; DAILY; DALTON; CANELLA, 2003). A título de exemplificação, Anderson e Reeb (2003)

\footnotetext{
${ }^{2}$ Segundo Fama e Jensen (1983a) são organizações em que a informação específica relevante para a tomada de decisão está concentrada em um ou poucos agentes.

${ }^{3}$ Segundo Fama e Jensen (1983a) são organizações em que o conhecimento específico para a tomada de decisões está diluído entre os diversos agentes.
} 
encontraram que, em consonância com a teoria da agência, empresas familiares que adotam conselheiros independentes são mais valiosas à medida que equilibram a influência da família sobre o board.

\subsubsection{Principal-Agente}

Eisenhardt (1989) apresenta outra linha de estudo dentro do contexto da teoria da agência, que possui uma abordagem mais abrangente, podendo ser aplicada a diferentes players como: empregador e empregado, comprador e fornecedor, advogado e cliente, entre outros. É importante ressaltar que o principal foco da dessa perspectiva teórica é determinar o melhor tipo de contrato entre as partes. Para isso, a autora apresenta um modelo inicial que assume os seguintes pressupostos:

a) existência de conflitos de interesse entre agente e principal;

b) facilidade de medir resultados; e

c) agente com maior aversão ao risco do que o principal ${ }^{4}$.

Segundo Eisenhardt (1989), o objetivo dessa corrente de pensamento é determinar o contrato ideal em dois cenários distintos. O primeiro cenário é caracterizado pela ausência de assimetria informacional entre as partes, ou seja, o principal conhece as atitudes do agente. Nesse contexto, um contrato baseado em comportamento se mostra mais eficiente. Casos em que a atuação do agente é de difícil observação, faz-se necessário o investimento em sistemas de informações que possam revelar o comportamento do agente ao principal.

O segundo cenário é quando o principal não tem conhecimento completo das atitudes do agente. O tipo de contrato que atende a esse modelo é essencialmente baseado emresultados, devido a sua facilidade de constatação. Porém, quando o objeto do contrato é um resultado, pode ocorrer problemas de imprevisibilidade de situações, como: políticas governamentais, atitudes de competidores, mudanças tecnológicas, entre outros. Nessa situação, portanto, a incerteza dos resultados está negativamente associada aos contratos baseados em performance. A partir da análise dos dois possíveis cenários, a autora conclui que há um trade-off entre custos de medição de comportamento e custos de medição de resultados na escolha do contrato que melhor atende à situação.

Eisenhardt (1989) ainda pontua a possibilidade de variações dos pressupostos que constituem o modelo básico de decisão de contratos. As variações envolvem: (a) longa duração da relação entre agente e principal; (b) possibilidade de programabilidade das atividades desempenhadas pelo agente e (c) não aversão ao risco por parte do agente. A combinação do relaxamento de cada um desses pressupostos exige tipos diferentes de contratos.

No que diz respeito à produção acadêmica dedicada a essa linha de pesquisa Eisenhardt (1989 p.81, tradução nossa) afirma: "Em comparação com a abordagem positivista, a abordagem principal-agente é abstrata e matemática e, portanto, menos acessível aos pesquisadores organizacionais." Assim, estudos que analisam o conflito de agência sob a ótica da teoria principal-agente são escassos na literatura.

\subsubsection{Contribuição e Críticas à Teoria da Agência}

A principal contribuição apresentada por Eisenhardt (1989) da Teoria da Agência para a literatura organizacional refere-se a importância dada aos sistemas de informação, em especial aos conselhos de administração como forma de controle do comportamento

\footnotetext{
${ }^{4}$ Nesse contexto, agente e principal podem assumir diversos papéis, tais como: proprietários e gestores, empregador e empregado, comprador e fornecedor, advogado e cliente, entre outros.
} 
oportunista do gestor. Esse mecanismo tem sua importância baseada na riqueza de informações que é capaz de proporcionar aos shareholders, o que conduz a uma menor assimetria informacional e maior criação de valor para a firma.

As críticas que giram em torno da teoria da agência são apresentadas por Davis et al., (1997). Os autores pontuam estudos (DOUCOULIAGOS, 1994; FRANK, 1991) que contestam a simplificação da natureza humana, reduzindo-a a um comportamento egoísta que não captura a complexidade de ações e pensamentos. Por se tratar de uma teoria que tem como pressupostos motivações individualistas e puramente racionais, esse modelo de ser humano simplificado também foi contestado por diversos autores ${ }^{5}$ da psicologia e sociologia que sugerem limites teóricos e o relaxamento de algumas dessas premissas.

Apesar das críticas à teoria da agência, esta ainda predomina nos estudos no campo da governança corporativa (DAILY et al., 2003). Foi realizado, pelos autores deste ensaio, um levantamento e análise bibliométrica de 114 artigos disponíveis na Coleção SciELO Brasil, extraídos mediante o software Mendeley. Os resultados indicaram que a vertente teórica mais utilizada como base para questões relacionadas ao tema é a teoria da agência, totalizando cerca de $52 \%$ das observações coletadas. A teoria dos stakeholders representa $6 \%$ dos total e a stewardship, cerca de $2 \%$ dos estudos $^{6}$. No que diz respeito ao cenário internacional,Kreuzberg e Vicente (2019) igualmente identificaram que a teoria da agência prevalece em estudos empíricos na temática da governança corporativa.

\subsection{TEORIA DOS STEWARDSHIP}

\subsubsection{Principais Conceitos}

A teoria do stewardship(DONALDSON; DAVIS, 1991) tem suas origens nos campos da psicologia e sociologia e defende que o agente também é motivado a agir no melhor interesse do principal. $\mathrm{O}$ modelo de ser humano adotado por essa perspectiva é de um ser coletivista, que percebe maior utilidade no bem coletivo do que no bem individual, visão que contrapõe um dos pressupostos básicos da teoria da agência de que os indivíduos agem apenas em função de seus interesses. Por envolver percepção de utilidade, os autores advogam um comportamento racional do ser humano, mesmo quando este não busca seus próprios objetivos, mas sim o bem geral. A necessidade de sobrevivência e satisfação pessoal dos gestores são supridas quando este age da melhor forma para a organização.

\subsubsection{Teoria do Stewardship vs. Teoria da Agência}

Davis et al. (1997) agrupam as diferenças entre as teorias da agência e stewardship em cinco fatores distintos: modelo de ser humano, mecanismos psicológicos, comparação social, questões situacionais e diferenças culturais. Conforme discutido anteriormente, o modelo de ser humano adotado por ambas as teoriasdifere significativamente à medida que a primeira assume a ideia de um homo economicusegoísta, enquanto a segunda abraça a concepção de um indivíduo auto-realizador e coletivista.

Os fatores psicológicos abrangem, entre outros, a motivação do indivíduo. Na teoria da agência essa motivação é de ordem mais baixa e inclui necessidades fisiológicas, de segurança e econômicas. Além disso, a relação de agência tem como foco motivações

\footnotetext{
${ }^{5}$ Principais autores da linha de finanças comportamentais (KAHNEMAN; KNETSCH; THALER, 1991; DE BONDT; THALER, 1985) criticam a concepção simplista do modelo de ser humano.

${ }^{6}$ A fundamentação teórica da restante das observações é composta pela Teoria baseada em Recursos (RBV), abordagens multi teóricas e teorias não explicitadas pelos autores.
} 
extrínsecas, ou seja, motivações tangíveis, que possuem valor de mercado. Já na relação de stewardship a motivação é de ordem mais alta e inclui crescimento e realizações. Essa teoria ainda presume que a motivação é intrínseca e envolve oportunidades de crescimento, conquistas e possibilidade de afiliação.

Ainda de acordo com Davis et al. (1997), a relação de agência está associada a baixos níveis de comprometimento enquanto a relação do stewardship está relacionada a altos níveis de engajamento e identificação com a organização. O uso do poder também difere entre as duas teorias. McCelland e Burnham (2003) definem o poder, dentro de uma organização, como uma necessidade psicológica de influenciar outros ao cumprimento e alcance de seus objetivos. O poder institucional, inserido no contexto da teoria da agência, depende da posição e do cargo ocupado pelo indivíduo. Já o pessoal, no âmbito da teoria do stewardship, não está associado a cargos, mas é construído ao longo do tempo por meio da identificação com as atitudes de quem possui o poder.

Os fatores situacionais referem-se a filosofia de gestão, orientação ao risco, prazos e objetivos. A gestão de uma organização pode ser direcionada para o envolvimento (os empregados são responsabilizados e desafiados, resultando no autocontrole sobre seus próprios comportamentos) ou destinadas para o controle (a execução e o controle são totalmente separados). Indivíduos que estão inclinados para uma situação de envolvimento, têm maior probabilidade de assumirem uma relação de stewardship. Alternativamente, indivíduos orientados para o controle têm maior predisposição a se engajarem em uma relação de agência. Do mesmo modo, a orientação ao risco, horizontes temporais e objetivos organizacionais diferem entre as duas teorias (ver Tabela 1).

Os aspectos culturais, igualmente, divergem entre as duas teorias. Hofstede (2001) apresenta seis dimensões ${ }^{7}$ que determinam a cultura dos indivíduos de uma nação, entre elas, o fator individualismo vs. coletivismo e distância do poder. Davis et al. (1997) apontam esses fatores como decisórios na escolha da relação entre principal e agente. Pessoas imersas em culturas coletivistas possuem maiores chances de desenvolver uma relação stewardship do que pessoas inseridas em culturas individualistas. Além disso, pessoas com menor distância de poder, ou seja, que dependem menos de membros mais poderosos em uma sociedade, são mais propensas a desenvolverem uma relação stewardship. Por outro lado, uma maior distância do poder proporciona condições favoráveis ao estabelecimento de uma uma relação de agência.

Tabela 1 -agencye stewardship: principais diferenças

Teoria da Agência

Econômico

Egoísta
Teoria Stewardship

Auto-realizador Coletivo
Comportamento

Mecanismos psicológicos

\footnotetext{
${ }^{7}$ As dimensões culturais identificadas por Hofstede (2001) incluem: individualismo vs. coletivismo; distância de poder; aversão à incerteza; masculinidade; orientação para o curto ou longo prazo e indulgência.
} 
Teoria da Agência, Stewardship e Stakeholders: Um Ensaio sobre sua Relevância no Contexto das Organizações

De ordem mais

Motivação

IdentificaçãoPoder

Outros gestores comprometimento

\author{
baixa/necessidades econômicas \\ (fisiológicas, segurança, econômica). \\ Extrínseca.
}

Baixa identificação e Institucional (legítimo, coercitivo)

\section{Mecanismos situacionais}

Filosofia gerencial Orientação ao risco PrazoObjetivos

Diferenças culturais

\author{
Baseada no controle \\ Mecanismos de controle \\ Curto \\ Controle de custos
}

Comparação social

\author{
De ordem mais alta \\ (crescimento, realização, auto- \\ realização). \\ Intrínseca.
}

\section{Principal}

Alta identificação e comprometimento

Pessoal (especialista, referência)

\author{
Baseada no \\ envolvimento \\ Confiança \\ Longo \\ Melhora da performance
}

\begin{tabular}{|c|c|c|}
\hline Diferenças culturais & $\begin{array}{c}\text { Individualismo } \\
\text { Maior distância de poder }\end{array}$ & $\begin{array}{l}\text { Coletivismo } \\
\text { Menor distância de }\end{array}$ \\
\hline
\end{tabular}

Fonte: Adaptado de Davis et.al. (1997)

Apesar das diferenças entre as teorias da agência e stewardship, a literatura do campo dos estudos organizacionais apresenta pesquisas em que os autores as utilizam não como concorrentes, mas como complementares. Madison et al. (2016), por exemplo, afirmam que o fato de as empresas implementarem mecanismos de controle, não as impede de adotar culturas coletivistas. Estudos no campo da Governança Corporativa como o de Garcia-Ramos e Garcia-Olalla (2014) utilizam-se de uma abordagem multi teórica para relacionar a estrutura dos conselhos de administração com o desempenho de empresas familiares. Assim, observase um indício do uso integrado das teorias acima discutidas.

\subsubsection{Escolha entre relacionamento de agência ou de stewardship}

Davis et al. (1997), a partir da teoria proposta por Donaldson e Davis (1991) constroem um framework (Figura 1) que integra teoria da agência e a teoria do stewardship. Ao considerarem no ambiente corporativo questões psicológicas, situacionais e culturais os autores explicam como se dá a escolha do relacionamento entre principal e agente. A partir do conteúdo exposto, Davis et al. (1997) apresentam quatro cenários que envolvem a combinação da escolha entre relações de agência ou de stewardshipfeitas pelo agente e principal. Essas escolhas dependem de características psicológicas, questões situacionais e background cultural de cada uma das partes.

A primeira situação, exposta no quadrante 4 do framework, mostra o resultado de agente e principal optarem por uma relação stewardshipque resulta namaximização do desempenho potencial do grupo. Por outro lado, quando ambas as partes optam por uma relação de agência, representado pelo quadrante 1 , o resultado é a minimização de custos potenciais. As duas outras situações (quadrantes 2 e 3), que envolvem escolhas mistas, resultam em desvantagem para a parte que optou por uma relação stewardshipe oportunismo para a parte que optou pela relação de agência. 
Teoria da Agência, Stewardship e Stakeholders: Um

Ensaio sobre sua Relevância no Contexto das Organizações

Figura 1 - modelo de escolha do principal-gestor

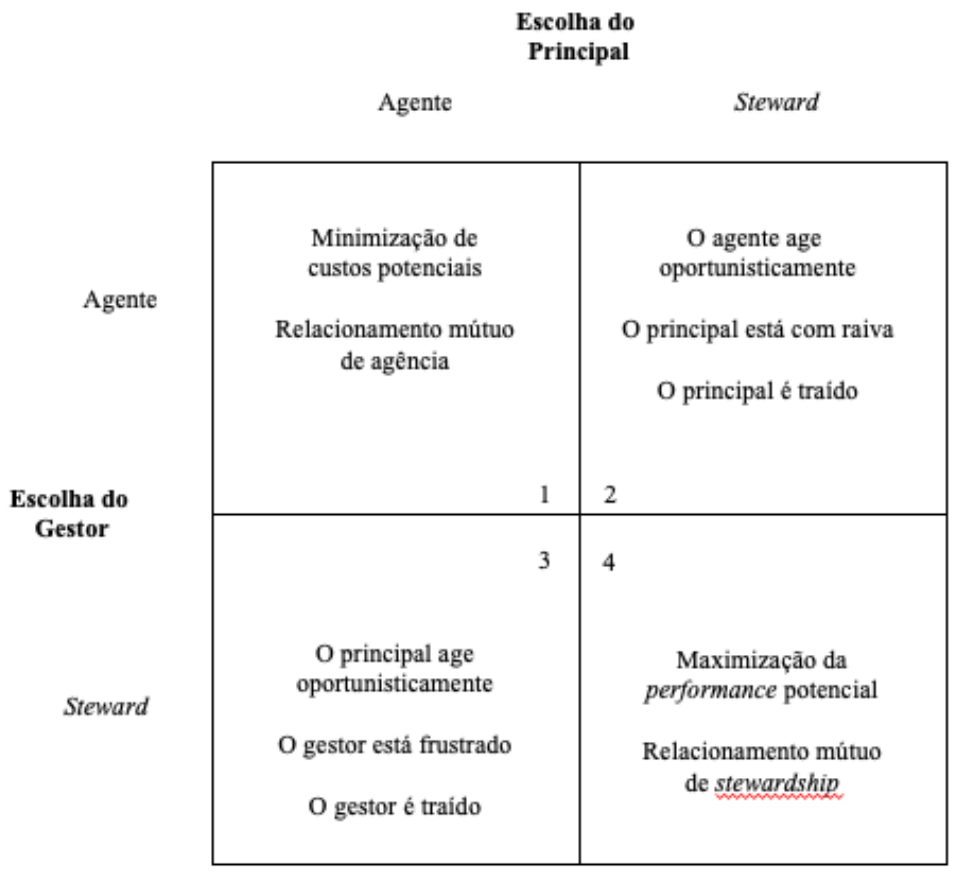

Fonte: Adaptado de Davis et al. (1997)

Complementando, a partir do framework proposto pelos autores, entende-se que enquanto a teoria da agência está restringida ao cenário em que agente e principal optam por uma relação de agência (quadrante 1), a teoria do stewardship expande essa visão mostrando que não obrigatoriamente as partes envolvidas escolherão perseguir seus próprios objetivos em função da maximização de seu bem estar. A stewardshiptheory, ao abrir quatro possíveis cenários diferentes, amplia e enriquece a visão das relações contratuais nas organizações. Ainda segundo Davis et al. (1997), apesar da aparente predominância da teoria do stewardship (quadrantes 2, 3 e 4), as partes tendem a optar por um comportamento de agência para minimizar o risco de ser traído pela outra parte.

\subsection{TEORIA DOS STAKEHOLDERS}

\subsubsection{Contextualização}

Freeman (1984 p. 59, tradução nossa) traz a seguinte definição para o termo stakeholders:"qualquer grupo ou indivíduo que afeta ou é afetado pelo alcance dos objetivos da empresa". Com essa proposição, o autor inclui neste grupo: acionistas, empregados, clientes, fornecedores, credores e a sociedade em geral. A teoria dos stakeholders é apresentada a partir da ideia de que todos os grupos que possuem qualquer interesse legítimo e que participem das operações da companhia o fazem para obter benefícios e, por essa razão, não cabe a priorização dos interesses de um grupo em detrimento de outros, conforme defende a Teoria dos Shareholders (FRIEDMAN, 1970).

A doutrina dos contratos justos, segundo Freeman (1984), embasa a teoria dos stakeholders à medida que propõe seis princípios fundamentais para guiar o comportamento das partes interessadas no estabelecimento das diretrizes corporativas. São eles: (1) princípio da entrada e saída. Qualquer contrato da corporação deve ter claramente definidos os meios de entrada, saída e condições de renegociação; (2) princípio da governança. Mudanças nas "regras do jogo" devem ser acordadas por consentimento unânime das partes; (3) princípio das externalidades. Se um contrato entre dois players impõe um custo para um terceiro, então esse deve ter a opção de fazer parte do contrato; (4) princípio dos custos de contratação. 
Todas as partes devem dividir os custos de contratação; (5) princípio da agência. O agente deve servir o interesse de todos os stakeholders; (6) princípio da imoralidade limitada. A corporação deve ser gerida de modo a servir os interesses dos stakeholders ao longo do tempo.

Dessa maneira, a teoria dos stakeholders defende que o papel da organização é gerenciar o relacionamento e interesses de todas as partes interessadas no processo de criação de valor. Além disso, defende a ideia de que as organizações devem ser socialmente responsáveis e geridas a serviço do interesse público (FREEMAN, 1984). Segundo Carroll (1999), a responsabilidade social corporativa (RSC) pode ser entendida como a abrangência dos compromissos assumidos pelas organizações nos âmbitos econômico, ético e legal. Da Silveira (2015) apresenta três faces da RSC: doação direta de recursos corporativos, utilização da RSC como forma de gerenciamento de riscos empresariais com o objetivo de evitar problemas com os stakeholders e a RSC como uma oportunidade de criação de valor aos acionistas. Nesse sentido, pesquisas sobre o tema vem crescendo nas últimas décadas (KIM; KIM; QIAN, 2018; SCHREMPF-STIRLING; PALAZZO; PHILLIPS, 2016).

Ainda neste contexto, Blair (1995) propõe uma reflexão a respeito da Governança Corporativa no século XXI. Em seu paper a autora argumenta que as empresas são, em sua essência, contratos institucionais que governam as relações entre todas as partes que contribuem para o alcance de seus objetivos. Para defender essa visão, Blair (1995) busca responder às seguintes questões: O que é uma corporação? Quais objetivos deve perseguir? Aos interesses de quem deve servir?

Segundo a autora, as corporações devem ser extensões legais de seus proprietários, ou seja, devem possuir os mesmos direitos e as mesmas responsabilidades de seus donos. Para responder às duas outras questões, Blair (1995) faz uma série de considerações a respeito da organização como entidade social. Até a década de 1980 a questão da RSC não era uma pauta amplamente discutida na esfera legal. A partir de então, as empresas que possuíam políticas voltadas para o bem-estar da comunidade começaram a ser melhor vistas pela sociedade em geral. Por exemplo, as cortes norte-americanas passaram a apoiar corporações que tinham a prática de fazer doações a museus e hospitais ou que de alguma maneira gastavam recursos da firma para o bem da comunidade (BLAIR, 1995).De acordo com a autora, apesar da aparente divergência de interesses no curto prazo, no longo prazo atender as necessidades dos stakeholders geraria um ambiente empresarial saudável para a continuidade dos negócios, e consequentemente, dos shareholders. Entretanto, mais tarde, a ideia da RSC começou a perder força, segundo Allen (1992), por três principais razões: aumento da competição global, internacionalização dos mercados financeiros e o surgimento de aquisições hostis.

Blair (1995) prossegue em sua argumentação ao expor e refutar os motivos apontados pela literatura que justificam a direção das companhias de modo a atender aos interesses dos shareholders. Uma das principais críticas da autora diz respeito à visão de que os shareholderssão os reclamantes residuais, que assumem os riscos e ganhos da operação. Para ela, não é verdade que esse grupo assume os riscos do negócio em sua totalidade, uma vez que estes, quando insatisfeitos, podem vender sua participação na companhia a qualquer momento. Ademais, sua proposição defende que, na verdade, o risco da operação é assumido pelos diversos stakeholders e para que estes estivessem totalmente imunes a tais riscos, deveriam dispor de contratos completos, que abrangessem todo e qualquer tipo de situação.

Dessa forma, o contraponto básico entre a teoria da agência e a teoria dos stakeholders reside na definição do grupo considerado como principal. Enquanto na primeira o principal é representado pelos acionistas e donos do negócio, na segunda os principais compreendem toda e qualquer parte relacionada à empresa. Algumas pesquisas, entretanto, consideram 
possível que os interesses de ambos sejam atendidos. O estudo de Garcia-Torea, FernandezFeijoo e de laCuesta (2016), por exemplo, analisa em que medida os conselhos de administração são capazes de proteger os interesses dos shareholders e, ao mesmo tempo, satisfazer as necessidades dos stakeholders.

\subsubsection{Críticas à teoria do stakeholder}

A crítica mais dura recebida pela teoria dos stakeholders é encontrada no trabalho de Milton Friedman (1970 p. 51, tradução nossa) intitulado: "The Social Responsibilityof Business toIncrease Its Profits". Nesse artigo o autor condena a prática da RSC ao afirmar que:

[...] o executivo estaria gastando o dinheiro de outras pessoas para suprir um interesse social geral. Apesar de suas ações estarem de acordo com sua 'responsabilidade social', essas reduzem os retornos dos acionistas, [...] aumentam o preço para os consumidores [...] diminuem a compensação dos empregados [...]. Os acionistas, consumidores e empregados poderiam, separadamente, gastar seu dinheiro em ações particulares se eles assim o quisessem.

Da mesma maneira, Tirole (2005) levanta quatro objeções a respeito da estrutura de governança baseada nos interesses dos stakeholders. A primeira diz respeito à cessão de igual direito de controle a investidores e não-investidores. Este fato pode resultar em uma dificuldade de obtenção de financiamento necessário para garantir as atividades empresariais, uma vez que as partes não possuem os mesmos incentivos para assumir os riscos associados ao negócio. A segunda refere-se à criação de ineficiências na tomada de decisões. Em diversas situações, investidores e stakeholders possuem interesses conflitantes, o que pode resultar em uma divergência de políticas decisórias.

A terceira objeção é em relação a responsabilidade gerencial. Enquanto o executivo que possui a responsabilidade de maximizar o valor para o acionista tem uma única e objetiva missão (lucro ou aumento de valor das ações), o executivo socialmente responsável enfrenta uma série de questões de difícil mensuração, tais como: (1) como devem ser medidos progressos nas áreas ambientais e sociais? (2) qual é o trade-off entre resultado financeiro, ambiental e social? (3) como acompanhar o desempenho de duas companhias, que naturalmente apresentam resultados distintos nas diferentes linhas de ação? (DA SILVEIRA, 2015). A quarta e última objeção é o fato de o êxito da pressão popular para a adoção de práticas socialmente responsáveis por parte das empresas resultar na imposição de uma espécie de taxa moral sobre as organizações, cujos recursos acabam por sair do controle de seus proprietários.

Sternberg (1999) também apresenta argumentos com o intuito de invalidar a teoria dos stakeholders. Na opinião da autora, como a abordagem não estabelece diretrizes claras para a identificação das partes envolvidas, é praticamente impossível trabalhar para o alcance do equilíbrio de interesses de todos os stakeholders. Além disso, Sternberg (1999) traz a ideia de que essa teoria não está de acordo com as boas práticas de governança, uma vez que concede aos executivos a possibilidade de perseguirem seus próprios interesses, em detrimento dos direitos dos demais envolvidos. A autora também ressalta que a definição de vários objetivos atrapalha o estabelecimento de metas claras, resultando em dificuldades estratégicas para a organização.

Apesar de os argumentos apresentados por Blair (1995) serem válidos e merecedores de atenção, eles não consideram as questões práticas que envolvem o comprometimento com responsabilidade social, as quais foram expostas por Tirole (2005) e Sternberg (1999). As dificuldades apresentadas por esses autores refletem a necessidade de aperfeiçoamento de aspectos práticos da teoria dos stakeholders. 


\section{CONCLUSÕES}

A teoria da agência traz significativas contribuições ao pensamento organizacional à medida que enfatiza a racionalidade econômica do ser humano e busca antecipar comportamentos oportunistas por parte dos gestores que poderiam comprometer a criação de valor para o acionista. Porém, por partir de pressupostos 'questionáveis', algumas teorias se propõem a refutar e apresentar alternativas que expliquem, de maneira mais adequada, as relações contratuais que envolvem o ambiente organizacional. Este ensaio trouxe a teoria dos stakeholders e teoria do stewardship, alguns dos seus principais representantes e estudos clássicos e recentes que discutem suas aplicabilidades no ambiente empresarial. $\mathrm{O}$ estudo também buscou realizar uma breve comparação entre suas ideias e aprofundar nas principais proposições de artigos que possuem grande relevância no estudo da governança corporativa (BLAIR, 1995; DAVIS et al., 1997; EISENHARDT, 1989; FAMA; JENSEN, 1983a).

A partir da análise e discussão das teorias, esse ensaio se posiciona em relação a dois aspectos. $\mathrm{O}$ primeiro aspecto tem relação com a complementaridade trazida pela visão do stewardship. Essa teoria por si só possui uma visão 'inocente' a respeito da natureza humana, mas quando utilizada em conjunto com a teoria da agência aperfeiçoa a visão dos diversos tipos de relação entre agente e principal nas organizações. $O$ segundo refere-se a complexidade dos fatores envolvidos na busca pela satisfação dos interesses dos stakeholders. A dificuldade de definir, de maneira clara, as partes interessadas, as metas e as prioridades, torna-a de improvável aplicação prática no ambiente corporativo. As limitações levantadas por diversos autores (FRIEDMAN, 1970; STERNBERG, 1999; TIROLE, 2005) em relação a teoria do stakeholder apenas contribuem para a consolidação da teoria da agência como principal norteadora do pensamento organizacional no âmbito da governança corporativa.

Considerando a crescente tendência de estudos multi teóricos, bem com a possível complementaridade das teorias apresentadas, diversos estudos podem ser realizados nesse sentido. Uma provável pesquisa empírica decorrente das considerações aqui apresentadas poderia testar se os principais e executivos são mais propensos a uma relação de agencyoustewardship, conforme o país de origem, gênero ou até mesmo setor em que atuam. Esse ainda é um campo que, devido a suas particularidades, tem se mostrado bastante fértil para pesquisa e indubitavelmente poderia ser explorado.

\section{REFERÊNCIAS}

ÅBERG, C., BANKEWITZ, M., KNOCKAERT, M. Service Tasks of Board of Directors: A Literature Review and Research Agenda in an Era of New Governance Practices. European Management Journal, 2019.

ALLEN, W. T. Our schizophrenic conception of the business corporation. Cardozo Law Review. 1992. 14(2):261-81

ANDERSON, R. C., REEB, D. M. Founding-family ownership and firm performance: evidence from the S\&P 500. The journal of finance, v. 58, n. 3, p. 1301-1328, 2003.

ARROW, K.J. Essays in the theory of risk-bearing. 1970.

BECHT, M., BOLTON, P., RÖELL, A. Corporate governance and control. In: Handbook of the Economics of Finance. Elsevier, 2003. p. 1-109. 
BERLE, A. A.; MEANS, G. C. 1932. The modern corporation and private property. New York: Commerce Clearing House, Inc.

BLAIR, M. M. Rethinking assumptions behind corporate governance. Challenge, v. 38, n. 6, p. 12-17, 1995.

CARROLL, A. B. Corporate social responsibility: Evolution of a definitional construct. Business \& society, v. 38, n. 3, p. 268-295, 1999.

COASE, R. H. The problem of social cost. In: Classic papers in natural resource economics. PalgraveMacmillan, London, 1960. p. 87-137.

DA SILVEIRA, A Di M. Governança corporativa no Brasil e no mundo: teoria e prática.Elsevier Brasil, 2015.

DAVIS, J. H.; SCHOORMAN, F. D.; DONALDSON, L. Toward a stewardship theory of management. Academy of Management review, v. 22, n. 1, p. 20-47, 1997.

DAILY, C. M.; DALTON, D. R.; CANELLA, A. A. Special Topic Forum on Corporate Governance: Corporate Governance: Decades of Dialogue and Data (introduction to special). Academy of Management Review, v. 28, n. 3, p. 371-382, 2003.

DE BONDT, W. FM, THALER, R. Does the stock market overreact? The Journal of finance, v. 40, n. 3, p. 793-805, 1985.

DONALDSON, L., DAVIS, J. H. Stewardship theory or agency theory: CEO governance and shareholder returns. Australian Journal of management, v. 16, n. 1, p. 49-64, 1991.

DOUCOULIAGOS, C. A note on the evolution of homo economicus. Journal of Economic Issues, v. 28, n. 3, p. 877-883, 1994.

EISENHARDT, K. M. Agency theory: An assessment and review. Academy of management review, v. 14, n. 1, p. 57-74, 1989.

FAMA, E. F., JENSEN, M. C. Separation of ownership and control. The journal of law and Economics, v. 26, n. 2, p. 301-325, 1983 a.

FRANK, R. H., CARTWRIGHT, E. Microeconomics and behavior. New York: McGrawHill, 1991.

FREEMAN, R. Strategic Management: A Stakeholder Approach. Boston: Pitman, 1984.

FRIEDMAN, M. A theoretical framework for monetary analysis. Journal of Political Economy, v. 78, n. 2, p. 193-238, 1970.

GARCÍA-RAMOS, R., GARCÍA-OLALLA, M. Board independence and firm performance in Southern Europe: A contextual and contingency approach. Journal of Management \& Organization, v. 20, n. 3, p. 313-332, 2014.

GARCIA-TOREA, N., FERNANDEZ-FEIJOO, B.; DE LA CUESTA, M. Board of director's effectiveness and the stakeholder perspective of corporate governance: Do effective boards promote the interests of shareholders and stakeholders? BRQ Business Research Quarterly, v. 19, n. 4, p. 246-260, 2016.

HOFSTEDE, G. Culture's consequences: Comparing values, behaviors, institutions and organizations across nations. Sage publications, 2001. 
JENSEN, M C.; MECKLING, H. Theory of the firm: Managerial behavior, agency costs and ownership structure. Journal of financial economics, v. 3, n. 4, p. 305-360, 1976.

KAHNEMAN, D., KNETSCH, J. L., THALER, R. H. Anomalies: The endowment effect, loss aversion, and status quo bias. Journal of Economic perspectives, v. 5, n. 1, p. 193-206, 1991.

KIM, K., KIM, M., QIAN, C. Effects of corporate social responsibility on corporate financial performance: A competitive-action perspective. Journal of Management, v. 44, n. 3, p. 1097-1118, 2018.

KREUZBERG, F., VICENTE, E. F. R. Where are We Heading? An Analysis of the Corporate Governance Literature. Revista de Administração Contemporânea, v. 23, n. 1, p. 43-66, 2019.

MADISON, K. Viewing family firm behavior and governance through the lens of agency and stewardship theories. Family Business Review, v. 29, n. 1, p. 65-93, 2016.

MCCLELLAND, D. C., BURNHAM, D. H. Power is the great motivator. 1976. Harvard business review, v. 81, n. 1, p. 117, 2003.

NORTH, D.C. Institutions, ideology, and economic performance. Cato J., v. 11, p. 477, 1991.

SCHREMPF-STIRLING, J., PALAZZO, G., PHILLIPS, R. A. Historic corporate social responsibility. Academy of Management Review, v. 41, n. 4, p. 700-719, 2016.

STERNBERG, E. The stakeholder concept: a mistaken doctrine. Foundation for Business Responsibilities, Issue Paper, n. 4, 1999.

TIROLE, J. The Theory of Corporate Finance. Princeton University, Press and copyrighted, 2005.

WILLIAMSON, O. E. The economics of organization: The transaction cost approach. American journal of sociology, v. 87, n. 3, p. 548-577, 1981.

WILSON, R. The theory of syndicates. Econometrica: journal of the Econometric Society, p. 119-132, 1968. 